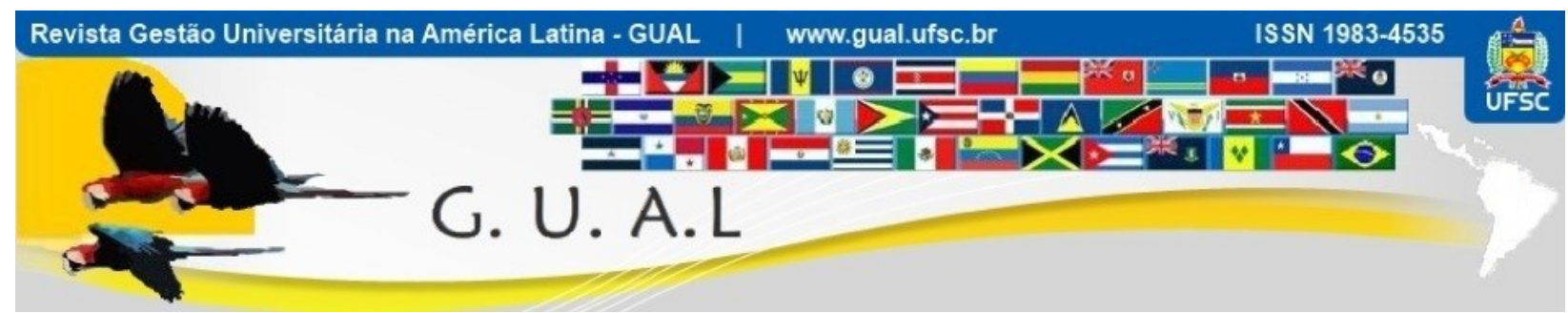

DOI: http://dx.doi.org/10.5007/1983-4535.2017v10n1p79

\title{
AVALIAÇÃO DO PROCESSO DE IMPLEMENTAÇÃO DE OBRAS PÚBLICAS EM UNIVERSIDADES FEDERAIS: UM ESTUDO DO PROGRAMA REUNI
}

\section{EVALUATION OF THE PROCESS OF IMPLEMENTATION OF PUBLIC WORKS IN FEDERAL UNIVERSITIES: A STUDY OF THE REUNI PROGRAM}

Maria Fernanda Nogueira Bittencourt, Mestre Ministério do Planejamento, Desenvolvimento e Gestão mariafernandabittencourt@hotmail.com

Patrícia Aparecida Ferreira, Doutora Universidade Federal de Lavras - UFLA paf@dae.ufla.br

Mozar José De Brito, Doutor Universidade Federal de Lavras - UFLA mozarbritto@gmail.com

Recebido em 04/agosto/2015

Aprovado em 02/dezembro/2016

Sistema de Avaliação: Double Blind Review

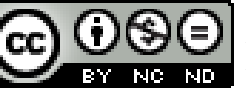

Esta obra está sob uma Licença Creative Commons Atribuição-Uso. 


\title{
RESUMO
}

Este trabalho foi realizado com o objetivo de avaliar o Programa REUNI no que concerne às obras de infraestrutura, de modo a identificar os principais fatores e condicionantes que contribuíram para a conclusão, atraso ou paralisação nas instituições federais de ensino superior, bem como os seus desdobramentos no atingimento das metas desse programa. Existe, atualmente, uma carência de estudos que relacionem obras com o ciclo de políticas públicas. Apesar do aumento da oferta de serviços públicos normalmente passar por ampliação da estrutura instalada, pouco se vê na literatura estudos que façam referência ao tema. O método empregado é o estudo de caso avaliativo, em que o objeto estudado é o REUNI, enquanto um programa governamental de reestruturação e ampliação do ensino superior federal, analisando os dados referentes às obras das cinquenta e três universidades federais participantes do programa, coletados a partir de uma pesquisa bibliográfica e documental. Dentre os achados do trabalho, verificou-se que o percentual de conclusão de obras é de $78 \%$; a equipe técnica de engenharia e arquitetura foi renovada e ampliada; as metas de pactuação de vagas e cursos foram superadas em números totais, bem como os recursos pactuados de investimento foram disponibilizados e até ampliados em $62,55 \%$. Apesar disso, alguns resultados demonstram que pouca atenção foi dada à questão de obras na formulação do REUNI, uma vez que muitas obras sofreram paralisações, revisões de projetos e aditivos de valor. Por fim, ressalta-se que para três quartos das universidades a não conclusão de alguma obra trouxe impactos negativos na implantação de novas vagas ou novos cursos, demonstrando, assim, a importância das mesmas no atingimento das metas pactuadas de uma política pública.

Palavras chave: REUNI. Obras. Ciclo de políticas públicas. Formulação. Implementação.

\begin{abstract}
This work was carried out to evaluate infrastructure projects of the REUNI Program, in order to identify the main factors contributing to its completion, delay or suspension in federal higher education institutions, as well as its consequences for the achievement of the goals of this Program. Currently there is a lack of studies correlating public works to the policy cycle. Despite the fact that increase in public service provision normally leads to an expansion of the installed structure, literature studies seldom refer to this subject. The method used in the work is the case study, where the studied object is REUNI, understood as a government program for restructuring and expansion of higher education federal. For this work, data collection and analyses of infrastructure work of the fifty-three federal universities participants REUNI collected from a bibliographic and documentary research. Among its findings, works completed has reached $78 \%$; engineering and architecture teams were renovated and enlarged; agreed vacancies and courses within the universities were surpassed in total numbers; while of contracted resource investment was available and also expanded in 62.55\%. Despite this, results show that little attention was paid to work in formulation of REUNI, as many works have suffered outages, project revisions and additives. Finally, it is noteworthy that for threequarters of universities the non-completion of any work brought negative impacts on implementation of new vacancies or new programs, thereby demonstrating the importance of work on the achievement of the agreed goals of a public policy.
\end{abstract}

Key words: REUNI. Public works. Policy cycle. Formulation. Implementation. 


\section{INTRODUÇÃO}

A implementação de muitas políticas públicas se faz com o aumento da oferta de serviços públicos, a qual, na maioria das vezes, requer também uma ampliação da infraestrutura instalada.

O Programa de Apoio a Planos de Reestruturação e Expansão das Universidades Federais (REUNI), instituído pelo Decreto $\mathrm{n}^{\circ}$ 6.096/2007, tem como objetivo principal “criar condições para a ampliação do acesso e permanência na educação superior, no nível de graduação, pelo melhor aproveitamento da estrutura física e de recursos humanos existentes nas universidades federais". Em seu escopo o Programa previa uma significativa expansão do número de vagas a serem criadas tanto em cursos novos quanto nos anteriores ao REUNI e também, em decorrência, a possibilidade de construção de novos câmpus a serem instalados no interior do País. Essa expansão no número de vagas decorreria da reestruturação dos cursos já existentes de graduação e também da abertura de mais de 628 novos cursos nos programas de pós-graduação, correspondendo a um aumento de 37,3\% dos cursos existentes em 2008 (RELATÓRIO DE GESTÃO 2012, MEC/SESu). A implementação do REUNI foi originalmente prevista para o período de 2008 a 2012. Para comportar tamanha ampliação da oferta de vagas nas universidades federais, foi planejada a construção e readequação de diversos espaços físicos, tais como: blocos de salas de aula, laboratórios, bibliotecas, salas de docentes, restaurantes universitários, espaços administrativos, moradias estudantis, espaços de convivência, etc. É importante lembrar que à época do lançamento do Programa, as universidades federais apresentavam carências em diversas áreas relacionadas às infraestruturas físicas então existentes e isso era resultado de um longo período de restrições orçamentárias que, por sua vez, geraram enormes gargalos em suas estruturas educacionais. Ademais, as equipes técnico-administrativas estavam desfalcadas e com pouca expertise na realização de atividades mais complexas relacionadas à contratação de obras de grande vulto. No período da publicação do Decreto do REUNI e, principalmente nos anos subsequentes, o mercado da construção civil também se encontrava aquecido, decorrente dos investimentos públicos e privados viabilizados por meio do Programa de Aceleração do Crescimento - PAC. Estes fatos podem ter contribuído para que as obras contratadas sofressem atrasos além do esperado. Diversas tiveram seus prazos de entrega adiados e muitas outras foram paralisadas ou até mesmo seus contratos foram cancelados. 
Passados mais de sete anos do lançamento do REUNI, esse trabalho procura realizar uma avaliação do andamento de suas obras, a partir da compreensão de algumas variáveis que se caracterizam como insumos e resultado dessa política. Como variáveis que representam alguns dos insumos dessa política foram utilizadas os recursos financeiros e a disponibilização dos mesmos, bem como quadro de profissionais especialistas em obra disponíveis. Como resultado utilizou-se a variável número de vagas e cursos pactuados versus ofertados. $\mathrm{O}$ trabalho está organizado em cinco seções além desta introdução. Inicialmente são apresentados alguns conceitos sobre políticas públicas, em especial sua implementação e as obras, sendo apresentada na sequência a metodologia utilizada. Posteriormente, o texto traz uma contextualização da criação e estruturação do REUNI e os resultados, bem como suas interpretações. Na última seção, são apresentadas as considerações finais.

\section{POLÍTICA PÚBLICA E OBRAS}

Existem diferentes definições sobre o que é política pública. Resumidamente, a política pública trata-se de um sistema de decisões públicas que visa a ações ou omissões, preventivas ou corretivas, destinadas a manter ou modificar a realidade de um ou vários setores da vida social, por meio da definição de objetivos e estratégias de atuação e da alocação dos recursos necessários para atingir os objetivos estabelecidos (SARAVIA; FERRAREZI, 2007). Complementando esse conceito, Rua (1997) argumenta que a política pública compreende um conjunto de procedimentos destinados a alocação de bens e recursos públicos; e que os atores envolvidos neste processo são diversos e possuem características distintas. Existem também diversas formas de analisar uma política. Baseando-se no estudo realizado por Dye (2009), Ferreira, Alencar e Pereira (2012) destacam alguns modelos referenciais: o institucional, o processual, o de grupo, o racional, o de elite, o incremental o da teoria dos jogos, o da opção pública e a sistêmica. No modelo processual, a política pública é concebida como um conjunto de processos político-administrativos (formulação, implementação e avaliação), que conformam um ciclo deliberativo, formado por vários estágios, constituindo um processo dinâmico e de aprendizado (FREY, 2000; SOUZA, 2006). A etapa de formulação pode ainda ser subdividida: em definição de agenda, avaliação das opções e seleção das opções.

A implementação pode ser compreendida como o conjunto de ações realizadas por grupos ou indivíduos de natureza pública ou privada, as quais são direcionadas para a 
consecução de objetivos estabelecidos mediante decisões anteriores quanto a políticas (RUA, 1997). Ferreira, Alencar e Pereira (2012), baseados em Kelma (2006), caracterizam a implementação como a fase em que a política pública se materializa, ou seja, como o processo de execução das políticas resultantes da formulação e decisão, sendo uma atividade orientada para o gerenciamento das pessoas e dos processos. Como complementa Oliveira (2006), a implementação de uma política pública pode ser vista como um meio de execução, ou seja, a etapa onde as políticas mudam e passam de diretivas administrativas para a prática, com uma declaração governamental de suas preferências, mediadas por um número de atores sociais que criam um processo circular caracterizado por relações recíprocas de poder e negociação. Rua (1997) orienta que a mera formulação de uma política e a consequente elaboração de um plano não garantem a viabilidade de sua implementação. Segundo esta autora, existem algumas pré-condições necessárias para que um política pública tenha uma boa implementação, tais como: o programa deve dispor de tempo e recursos suficientes; em cada estágio da implementação deve haver a combinação de recursos necessários para cumprir os objetivos; é necessário que haja compreensão e consenso quanto aos objetivos a serem atingidos; as tarefas a serem realizadas por cada participante devem estar com detalhes completos e em sequência perfeita. Ainda sobre isto, Howlett, Ramesh e Perl (2013) advertem que os policy-makers têm de se empenhar para conseguir uma combinação ótima de objetivos e meios no processo de implementação com vistas a alcançarem seus objetivos com êxito, e que este processo traz diversos desafios e riscos de insucesso. Corroborando com essa visão, Faria (2012) destaca que o processo de implementação pode ser o principal responsável pelo baixo impacto das políticas públicas e acrescenta ainda que nesta etapa do ciclo, as burocracias públicas não são neutras, o que desencadeia diferentes escolhas e decisões.

Deve-se lembrar ainda que para muitas políticas públicas serem implementadas, principalmente, quando há a previsão do aumento da oferta de serviços públicos, existe a necessidade de ampliação da infraestrutura instalada, o que resulta na execução de uma obra pública, a qual pode demandar grandes dispêndios e esforços para sua consecução. Entende-se por obra pública qualquer intervenção espacial, urbana ou rural, empreendida pelo Poder Público e que possua, em geral, interesse público. Desta forma, construções, reformas, recuperação ou ampliação de um bem público são consideradas obras públicas (Lei 8.666/93).

Como lembra Cohen (2007), em momentos como o da grande depressão dos anos 30, o governo dos Estados Unidos da América utilizou-se de programas de execução de obras 
públicas para estimular o mercado e consequentemente gerar empregos. É claro que o momento atual é outro, e como ressaltam Driessen, Glasbergen e Verdass (2001), o planejamento e execução de obras públicas tem se tornado cada vez mais complexo. Hoje em dia, é preciso que se leve em consideração não apenas problemas técnicos, mas também outros aspectos, como: a otimização de recursos, a conservação do meio ambiente e a qualidade de vida. Estes autores lembram ainda que, muitas vezes, para se atingir os resultados desejados, é necessário o envolvimento neste processo de diversos atores, como: diferentes esferas governamentais, o setor privado e outros grupos de interesse. No caso específico do Brasil, além de todos os aspectos citados acima, é importante que se considere também a legislação em vigor. Além da Lei 8.666/93 que rege as licitações e contratações públicas, existem as legislações locais que devem ser obedecidas. Outro fator a ser considerado neste processo diz respeito a uma variável exógena: o comportamento do mercado da construção civil. Nos últimos anos, em decorrência de investimentos públicos e privados viabilizados por meio do PAC, este mercado tem se mostrado bastante aquecido. Sendo assim, com tantas variáveis envolvidas, o planejamento de obras públicas se torna uma etapa vital para garantir a implementação e o sucesso de uma política pública.

Como qualquer política pública, aquelas que envolvem obras públicas devem ser avaliadas para possíveis correções tanto no início, quanto em sua execução e no seu término. De acordo com Frey (2000), avaliar uma política trata de indagar os déficits de impacto e os efeitos colaterais indesejados para poder deduzir consequências para ações e programas futuros. Esta avaliação poderá levar à suspensão ou fim do ciclo da política, ou mesmo, ao início de uma nova fase de elaboração de um novo programa ou modificação do programa anterior. A avaliação assim se torna imprescindível para o desenvolvimento e a adaptação contínua das formas e instrumentos de ação pública. Costa e Castanhar (2003) também corroboram com essa visão, destacando que a avaliação é uma etapa permanente e que não deve ser compreendida como uma fase final do ciclo de política pública, pois permeia também as fases de formulação e implementação, apontando os seus avanços e limites.

Pautado pelos tipos de avaliação, Ramos e Schabbach (2012) destacam que a avaliação na fase da implementação geralmente privilegia o exame da eficiência e eficácia de uma política pública, tende a ser caracterizada como uma avaliação de processo. Este tipo de avaliação procura detectar, periodicamente, as dificuldades que ocorrem durante o processo de implementação, a fim de se efetuarem correções ou adequações. Ela permite identificar se 
a política está sendo realizada conforme o previsto; os fatores que influenciam na implementação; propicia suporte para melhorar a eficiência operativa e a eficácia dos programas, disponibilizando resultados e informações úteis aos gestores. $\mathrm{Na}$ visão de Oliveira (2013), a avaliação de uma política pública deve ser orientada por medidas de desempenho, que são estimativas, quantitativas ou qualitativas, acerca de como as tarefas estão sendo desempenhadas e quais são os efeitos das atividades produzidas. As medidas de desempenho mais utilizadas são caracterizadas como: i) insumos: recursos financeiros, pessoal, equipamentos, etc.; ii) resultados: atividades desenvolvidas e serviços prestados; iii) impacto: efeito produzido pelo resultado alcançado; iv) produtividade: capacidade de solução de problemas registrados; v) custos: custos médios para a produção dos serviços prestados; vi) satisfação do usuário: queixas recebidas, resultados de pesquisa de opinião; vii) qualidade do serviço: disponibilidade e adequação do serviço procurado. Ainda segundo essa autora, essas medidas de desempenho auxiliam o processo de avaliação na medição de três fatores importantes para discussão de políticas públicas: i) eficiência: relação entre insumos e resultados; ii) eficácia: êxito do programa, capacidade demonstrada pelo projeto de atingir os objetivos e metas previamente estabelecidos; foca-se nos resultados; iii) efetividade: capacidade que os resultados tem de produzir mudanças duradouras e significativas. Como as obras públicas representam um meio importante para que algumas políticas públicas alcancem os seus objetivos, torna-se importante proceder a uma avaliação desse fator importante para implementação de uma política pública, no caso a ser estudado do REUNI.

\section{PROCEDIMENTOS METODOLÓGICOS}

Considerando o REUNI como objeto de estudo, adotou-se neste trabalho o método estudo de caso descritivo para realizar então uma avaliação do andamento das obras desse programa. Para tanto, foram analisadas as seguintes variáveis relacionadas com as obras: i) investimento; ii) quadro técnico específico (arquitetos e engenheiros); iii) metas do Programa: vagas e cursos; iv) situação das obras: concluídas, em execução, em licitação e paralisadas. Quanto aos meios de investigação, esta pesquisa se caracteriza como bibliográfica e documental. O levantamento de dados qualitativos e quantitativos ocorreu em momentos diversos, sendo que as principais fontes foram: i)documentos públicos anteriormente publicados (MEC e outros); ii) artigos publicados sobre a avaliação do Programa REUNI; iii) legislação vigente; iv) Sistema Integrado de Administração Financeira do Ministério da 
Fazenda (SIAFI/MF); v) Sistema Integrado de Monitoramento Execução e Controle do Ministério da Educação (SIMEC/MEC);vi) Sistema Integrado de Administração de Recursos Humanos do Ministério do Planejamento Orçamento e Gestão (SIAPE/MPOG); Censo da Educação Superior - INEP. A sistemática adotada para o tratamento dos dados consistiu na organização e análise de todas as informações obtidas das fontes documentais, dispondo, quando possível, os dados em gráficos de frequência a fim de tornar mais clara a visualização dos mesmos. Os dados coletados não tiveram identificação por sigla de cada universidade e as instituições foram denominados como Univ1, Univ 2.

\section{O REUNI}

Para que se compreenda o contexto e a base de criação do REUNI, é necessário que se resgate um pouco da evolução histórica da educação superior no Brasil. Trindade (1999) demonstra que a mesma iniciou-se atrasadamente quando comparada aos países latinoamericanos de língua espanhola, nos quais as universidades começaram a serem implantadas nas primeiras décadas após o descobrimento. No Brasil, este processo foi iniciado tardiamente e apenas à época da vinda da família real, sendo que a organização da educação superior em universidade foi implementada com a criação da Universidade do Rio de Janeiro, em 1920.

Em 1960, a Taxa de Escolarização Bruta na Educação Superior (razão entre o total de matrículas, independente da idade do total de matriculados e a população na faixa etária de 18 a 24 anos) era de somente 1\%, sendo que a mesma evoluiu até o ano de 2002 para 15\% (PINTO, 2004). Segundo este mesmo autor, apesar do incremento de matrículas, esse aumento se deu de forma bastante distinta entre as redes pública e privada. Enquanto no mesmo período as matrículas na rede privada cresceram 59 vezes, na rede pública o aumento foi de 20 vezes, tornando o Brasil um dos países com mais elevado grau de privatização desse nível de ensino. Weska (2012), por sua vez, relaciona que esse contexto de privatização da educação superior, com a consequente redução dos investimentos do Estado no setor, culminou numa política de estagnação das instituições universitárias federais. Durante anos essas instituições receberam pouco ou nenhum recurso para investir na construção de novas instalações ou ainda para a aquisição de equipamentos. De forma semelhante, a manutenção das instalações existentes foi sendo negligenciada em função da escassez de recursos (LUGÃO ET AL., 2012). As instituições careciam de equipamentos e faltavam livros na biblioteca (MELO; SANTANA, 2010). Sofriam, sobretudo, com a redução gradual de seu 
corpo docente e técnico-administrativo, que não era reposto no caso de aposentadorias ou outros tipos de vacâncias (LUGÃO ET AL., 2010).

Esse quadro, no entanto, começou a ganhar novos contornos com a publicação do Plano Nacional de Educação (PNE - Lei no 10.172, de 09 de janeiro de 2001), que procurou estabelecer metas que exigiam um aumento considerável de investimentos nesta área, para cumprir o que estava determinado na Constituição Federal de 1988. Em 2003, os reitores das universidades federais entregaram ao Presidente da República um documento intitulado de “Proposta de Expansão e Modernização do Sistema Público Federal de Ensino Superior" onde propunham uma série de metas necessárias à expansão e modernização dessas instituições. Cabe ressaltar ainda, que no ano de 2006, houve um movimento intitulado de Universidade Nova, encabeçado pelo então reitor da Universidade Federal da Bahia, Prof. Dr. Naomar Monteiro de Almeida Filho. Este movimento buscava uma solução contra a obsolescência das universidades de modelo tradicional e tinha como marcos inspiradores o Processo de Bolonha, os colleges estadunidenses e as contribuições do educador Anísio Teixeira, que defendia que a educação não pode jamais ser privilégio de alguns.

Neste contexto, foi instituído o REUNI pelo Decreto n. ${ }^{\circ} 6.096$ de 24 de abril de 2007, que além de buscar atender a diversas reinvindicações e a metas estabelecidas no PNE, pautou-se pela necessidade de expansão e reordenamento da educação federal superior no Brasil. Em seu artigo $1^{\circ}$, este Decreto define o objetivo e a meta global do REUNI.

Art. $1^{\circ}$ Fica instituído o Programa de Apoio a Planos de Reestruturação e Expansão das Universidades Federais - REUNI, como o objetivo de criar condições para a ampliação do acesso e permanência na educação superior, no nível de graduação, pelo melhor aproveitamento da estrutura física e de recursos humanos existentes nas universidades federais.

$\S 1^{\circ}$ O Programa tem como meta global a elevação gradual da taxa de conclusão média dos cursos de graduação presenciais para noventa por cento e da relação de alunos de graduação em cursos presenciais por professor para dezoito, ao final de cinco anos, a contar de cada plano.

O REUNI integrava uma política nacional de consolidação e expansão da educação superior federal, que previa o provimento da oferta de educação superior para pelo menos $30 \%$ dos jovens na faixa etária de 18 a 24 anos, até o final de 2010 (PNE - Lei n ${ }^{\circ}$ 10.172). O programa consistia em uma chamada pública não concorrencial para seleção e apoio aos Planos de Reestruturação e Expansão previamente aprovados pelos conselhos superiores das universidades federais. A adesão era facultativa, porém 53 universidades federais aderiram a este Programa o que, à época, representava a totalidade das mesmas. Os Planos de 
Reestruturação e Expansão apresentados deveriam contemplar e atender às diretrizes descritas no artigo $2^{\circ}$, do Decreto $n^{\circ} 6.096 / 2007$ :

\footnotetext{
I - redução das taxas de evasão, ocupação de vagas ociosas e aumento de vagas de ingresso, especialmente no período noturno;

II - ampliação da mobilidade estudantil, com a implantação de regimes curriculares e sistemas de títulos que possibilitem a construção de itinerários formativos, mediante o aproveitamento de créditos e a circulação de estudantes entre instituições, cursos e programas de educação superior;

III - revisão da estrutura acadêmica, com reorganização dos cursos de graduação e atualização de metodologias de ensino-aprendizagem, buscando a constante elevação da qualidade;

IV - diversificação das modalidades de graduação, preferencialmente não voltadas à profissionalização precoce e especializada;

$\mathrm{V}$ - ampliação de políticas de inclusão e assistência estudantil; e

VI - articulação da graduação com a pós-graduação e da educação superior com a educação básica.
}

Após terem sido analisados em função de sua consistência, exequibilidade e atendimento ao disposto no Decreto que instituiu o programa, foram estabelecidos acordos de meta, que envolveram repasse de recursos contemplando gastos de custeio e contração de pessoal, bem como investimentos destinados à aquisição, instalação e manutenção de equipamentos; e construção, ampliação e recuperação de instalações físicas. Segundo Weska (2012), o REUNI configurou-se como uma espécie de contrato estabelecido entre o MEC e as Universidades Federais para ampliação e melhoria da qualidade do ensino superior, contrato este viabilizado por recursos financeiros e de pessoal que serviram como suporte de indução e incentivo. Dentre os resultados desta expansão, iniciada em 2008 e com previsão inicial de término para 2012, vale destacar que em 2007, a rede federal de educação superior ofertava aproximadamente 140 (cento e quarenta) milhões de vagas em educação presencial, sendo que em 2012 este número alcançou 243 (duzentos e quarenta e três milhões) milhões de vagas (SINOPSE DAS AÇÕES DO MINISTÉRIO DA EDUCAÇÃO, 2012). O REUNI ampliou o espectro de atendimento da educação superior pública, contemplando municípios do interior e oferecendo aos jovens dessas regiões mais longínquas a oportunidade do acesso à universidade. Este processo de interiorização elevou o número de municípios atendidos por universidades federais de 114 (cento e quatorze) para 272 (duzentos e setenta e dois) (ANÁLISE SOBRE A EXPANSÃO DAS UNIVERSIDADES FEDERAIS 2003 a 2012).

Com vistas a garantir a infraestrutura necessária a expansão e reestruturação pretendida pelo programa, foi incluído nos Planos de Reestruturação e Expansão, apresentados por cada umas das universidades, uma parte específica referente à infraestrutura, 
chamado de Plano Diretor de Infraestrutura Física. Tal Plano deveria conter todas as características, custos e prováveis localizações dos serviços a serem realizados (construções, reformas e ampliações). Os custos de construção tiveram como referência o Sistema Nacional de Pesquisa de Custos e Índices da Construção Civil - SINAPI, em obediência à exigência contida na Lei de Diretrizes Orçamentárias - LDO, que assim o determina desde o ano de 2003. O MEC constituiu, então, um grupo assessor (Portaria $n^{0} 552$, de 25 de junho de 2007) com vistas a realizar análises dos Planos, verificando assim sua conformidade ao Decreto $\mathrm{n}^{\circ}$ $6.097 / 2007$ e às diretrizes posteriormente elaboradas. Ressalta-se que as análises foram direcionadas a parte acadêmica; a formulação de políticas de inclusão, assistência social e extensão universitária; e de cumprimento de indicadores, tais como: aumento do número de vagas e cursos, redução das taxas de evasão e ocupação de vagas ociosas, relação alunos de graduação por professor. As análises realizadas no tópico de infraestrutura se limitaram a verificar se os custos estavam referenciados pelo SINAPI. Foram destinados inicialmente R\$ 2,4 bilhões de reais para a realização das intervenções previstas - construções, reformas, ampliações e aquisição de equipamentos, não incluídos nesse valor as despesas com custeio e pessoal (MEC, SESu, DIFES). Este recurso seria concedido "na medida da elaboração e apresentação dos respectivos planos de reestruturação" (Art. $3^{\circ}$, Decreto n ${ }^{\circ}$ 6.907/2007).

As universidades tiveram um exíguo prazo para elaborar seus Planos de Reestruturação e Expansão. Como lembram Lugão et al. (2012), o REUNI foi instituído em abril de 2007, sendo que as Universidades deveriam apresentar suas propostas até novembro daquele mesmo ano. $\mathrm{O}$ estudo apresentado por estes autores mostra também que não houve uma estratégia claramente definida para a elaboração destas propostas. Cada universidade elaborou sua proposta conforme julgou ser mais adequado. Com relação à parte de infraestrutura física, não existiam projetos prontos que pudessem ser replicados e após muitos anos com baixa aplicação de recursos, as equipes de engenharia destas instituições estavam desmotivadas e desfalcadas. Melo e Santana (2010) lembram que apesar de todas as instituições terem aderido ao Programa, sua aprovação não foi pacífica nem democrática. A comunidade acadêmica esperava que a proposta fosse debatida e votada através de um plebiscito. Entretanto a adesão ao REUNI foi decidida apenas nos Conselhos Universitários. Uma outra crítica dirigida ao REUNI tratava da questão dos recursos financeiros. Havia um certo grau de incerteza quanto à chegada dos mesmos, pois a distribuição de recursos só se daria após o cumprimento de algumas metas, dependendo da disponibilidade financeira do 
MEC. Alegava-se, à época, que primeiro os estudantes chegariam à universidade para depois os recursos serem repassados. Assim os primeiros estudantes ingressariam em instituições com estruturas precárias (MELO; SANTANA, 2010). Ainda com relação aos recursos financeiros, vale destacar que como o incremento deste estaria vinculado a apenas $20 \%$ das despesas de custeio e pessoal da universidade, ao longo da implementação do Programa, algumas universidades cobraram uma repactuação junto ao MEC, pois alegavam que seus projetos haviam sido mal planejados devido ao curto prazo oferecido, e, portanto, necessitavam de aporte complementar de recursos (LUGÃO ET AL., 2012).

\section{REUNI EM NÚMEROS}

Com intuito de avaliar as obras previstas no REUNI, torna-se necessário compreender algumas variáveis, tais como os investimentos, o quadro técnico nas áreas de arquitetura e engenharia, bem como o número de vagas e cursos pactuados e realizados no Programa. Caracterizadas então essas variáveis, avalia-se então o estado das obras previstas no REUNI.

\subsection{REUNI - INVESTIMENTOS}

O documento Diretrizes Gerais (2007) previu um aporte de recursos de investimento da ordem de dois bilhões de reais. Este documento descrevia também que: "uma parte deste total de recursos, correspondendo a 500 milhões de reais será alocada considerando-se o número de matrículas projetadas com base nos dados consolidados PingIFES 2005. O valor restante, da ordem de 1,5 bilhão será distribuído considerando-se um valor de referência SESu de cinco mil reais para cada nova matrícula projetada." O MEC, porém, ao avaliar o desenvolvimento do Programa, constatou a necessidade de recursos de investimento adicionais. As universidades, ao elaborarem seus Planos Diretores de Infraestrutura Física, devido ao curto período de tempo, realizaram estimativas das áreas que seriam necessárias ao atendimento da expansão pretendida. Diversas calcularam os recursos necessários tomando-se como referência o custo total da área estimada multiplicada por apenas o custo por metro quadrado de uma construção preconizado pelo SINAPI. O custo SINAPI, porém, não considera alguns itens, como: execução de projetos, licenças necessárias, serviços preliminares, fundações especiais, instalações provisórias, ligações de água, energia elétrica e esgoto, equipamentos mecânicos, instalações especiais, impermeabilização, lucro da construtora e incorporadora - BDI (Benefícios e Despesas Indiretas), instalações de combate a 
incêndio, instalações de lógica, entre outros. Além disso, nestas estimativas muitas vezes foram esquecidas a parte de infraestrutura necessária à construção ou ampliação de prédios, como acessos, estacionamentos, redimensionamento e construção de subestações de energia elétrica, etc.

Foram então definidos complementos em momentos distintos, o primeiro em 2010/2011 e o segundo 2012/2013. Estes complementos foram calculados na seguinte forma: i) Complemento I: $50 \%$ (cinquenta por cento) da base originária de cálculo do REUNI Base REUNI 2007 (Total Pessoal e Benefícios PLOA 2007 + OCC Ajuste SESU sobre a $1^{\circ}$ Versão MATRIZ 2008, NFTE 2005); Complemento II: percentual de 40\% do valor de investimento recebido em 2011. No Gráfico 1 são apresentados os montantes totais distribuídos pelo Programa. Observa-se que os recursos iniciais disponibilizados foram de 2,43 bilhões de reais, sendo que houve um complemento em 2010-2011 de 1,06 bilhões e de 0,46 bilhão no período de 2012-2013, somando um investimento total de 3,95 bilhões. Portanto, como pode ser visto neste gráfico, houve a disponibilização efetiva não somente dos recursos pactuados, como ainda houve um complemento de $62,55 \%$ do montante inicial, atendendo, assim, o quesito de disponibilização de recursos para implementação das ações do REUNI, dentre os quais se destacam obras para ampliação de infraestrutura.

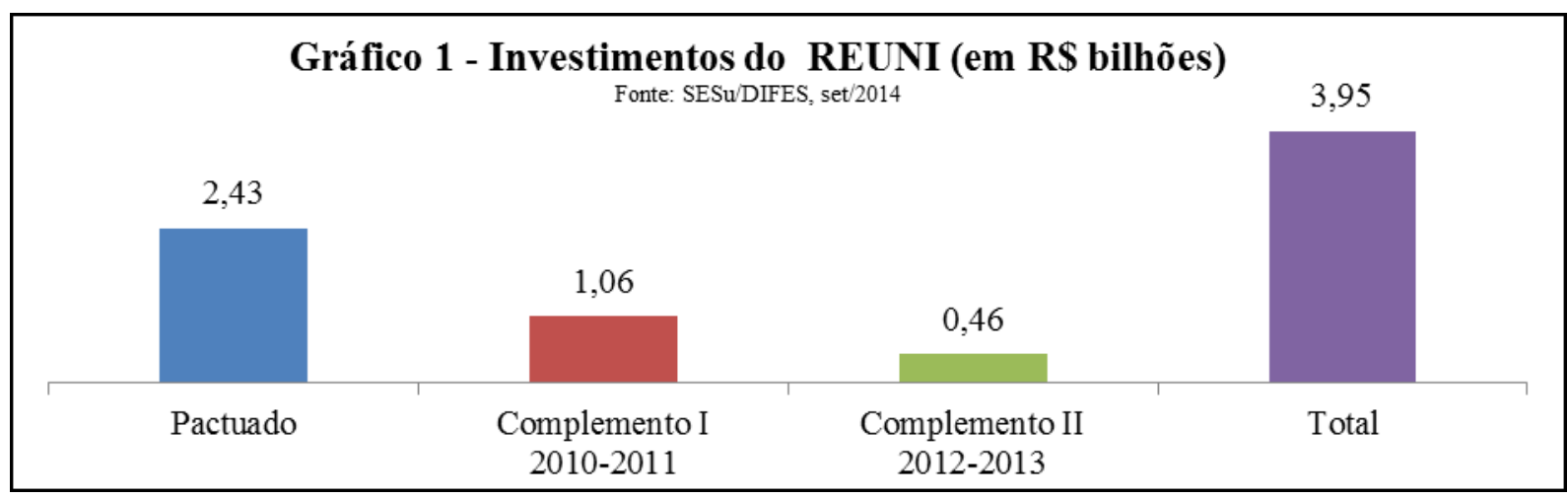

\subsection{REUNI - QUADRO DE TÉCNICOS NAS ÁREAS DE ARQUITETURA E ENGENHARIA}

O Gráfico 2 apresenta a evolução dos técnicos das áreas de arquitetura e engenharia no período de implementação do REUNI (2008 a 2014). Observa-se um aumento no número de arquitetos e engenheiros, sendo que o número de engenheiros teve uma elevação mais intensa de 55,1\% no período analisado de 2008 a 2014, enquanto o número de arquitetos aumentou em $29,5 \%$. No entanto, este aumento no número de arquitetos e engenheiros nem sempre pode 
ser verificada quando se observam os dados individualizados de cada universidade, conforme demonstra o Gráfico 3.

\begin{tabular}{|c|c|c|c|c|c|c|c|c|}
\hline \multicolumn{9}{|c|}{$\begin{array}{c}\text { Gráfico } 2 \text { - Servidores de áreas técnicas nas Universidades Federais } \\
\text { Fonte: SIAPE, } 2014\end{array}$} \\
\hline 1500 & & & & 1267 & 1356 & 1381 & 1502 & \multirow{2}{*}{-Total } \\
\hline \multirow{2}{*}{1000} & 1014 & 1094 & 1215 & 936 & 1005 & 1024 & 1138 & \\
\hline & 733 & 796 & 889 & 936 & & & & -Engenheiro \\
\hline \multirow[t]{2}{*}{500} & 281 & 298 & 326 & 331 & 351 & 357 & 364 & \multirow{2}{*}{$\begin{array}{l}\text {-Arquiteto e } \\
\text { urbanista }\end{array}$} \\
\hline & 2008 & 2009 & 2010 & 2011 & 2012 & 2013 & 2014 & \\
\hline
\end{tabular}

O Gráfico 3 demonstra que em 41 de 53 universidades que aderiram ao REUNI, esta variação foi inferior a 10 servidores destas áreas técnicas, sendo que para 27 delas esta variação não alcançou nem o acréscimo de 5 técnicos e para quatro, esta variação foi até mesmo negativa, ou seja, no início deste programa a instituição contava com um quantitativo maior de técnicos destas áreas do que ao seu final. Vale destacar que a questão de contratação de servidores técnicos para estas áreas ocorrem de acordo com a autonomia de cada universidade, entretanto, observa-se que os resultados indicam que nem todas as universidades fizeram a opção de contratar esse perfil profissional técnico, que é tão essencial para o acompanhamento de todo o processo de implantação de uma obra, incluindo desde a elaboração de projetos até sua efetiva conclusão. Há que se considerar também que existem algumas dificuldades para fixação destes profissionais, já que o mercado de construção civil encontra-se bastante aquecido e os salários pagos por estas instituições não tem o poder de atraí-los e mantê-los. Por outro lado, verifica-se que algumas universidades, como por exemplo, a universidade 47 que apresenta um número considerável de arquitetos e engenheiros. Acredita-se que relação do número de arquitetos e de engenheiros e o estado das obras do REUNI em cada universidade depende também da contextualização de outros fatores como porte da universidade, número de campus que integram a universidade, projetos em desenvolvimento, bem como da forma de gestão adotada (muitas universidades passaram a contratar profissionais terceirizados, ou mesmo empresas, para o desenvolvimento de seus projetos e o acompanhamento e fiscalização de suas obras, reduzindo desta forma a necessidade deste tipo de quadro técnico). 


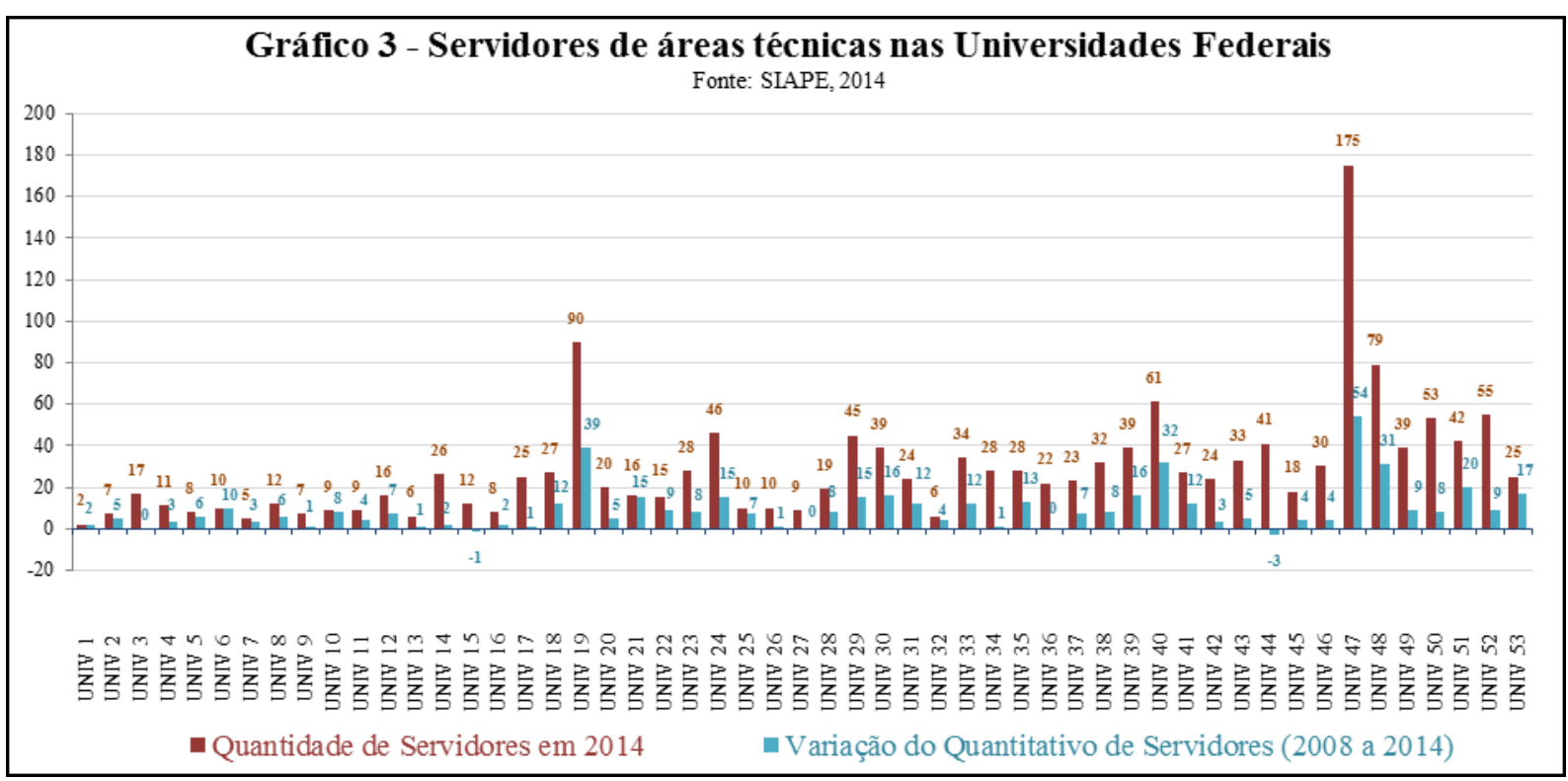

5.3 REUNI - Vagas e cursos pactuados e realizados
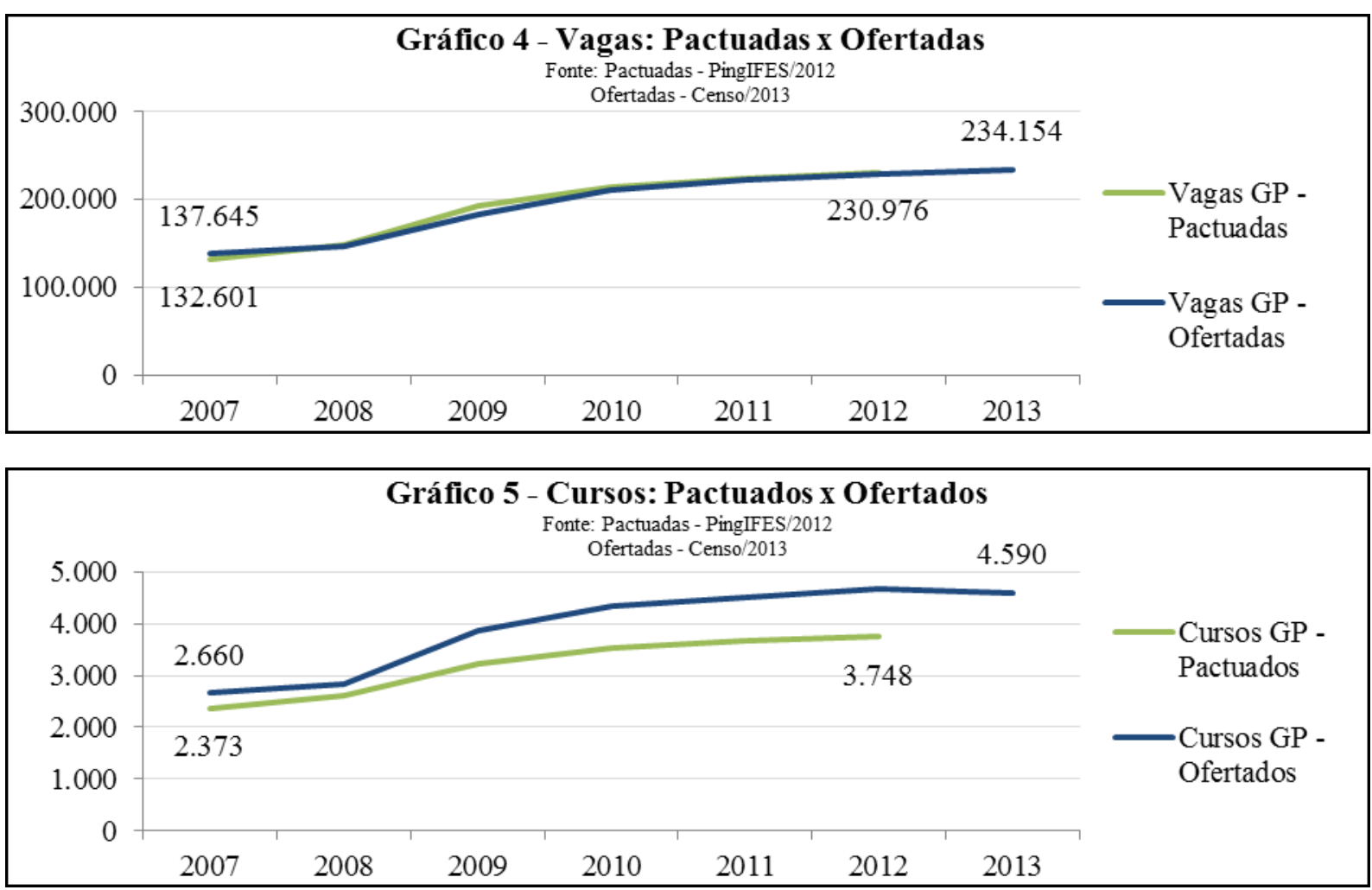

Nos Gráficos 4 e 5 são apresentadas as curvas de pactuação versus a oferta de vagas e cursos para a graduação presencial. Nota-se que tanto para vagas, como para cursos, o número alcançado pelo conjunto das universidades que aderiram ao REUNI estão muito próximas das metas estabelecidas. Há um pequeno atraso para algumas universidades, porém isto pode ser 
explicado principalmente pelo atraso sofrido na liberação de vagas para docentes. Os resultados indicam que o REUNI tem atingido a sua meta tanto de número de vagas como de cursos ofertados.

O Gráfico 6 demonstra a progressão de vagas realizadas entre 2007 e 2013, é possível verificar que, na totalidade das universidades que aderiram ao REUNI, as vagas foram ampliadas. O percentual médio de aumento das vagas foi de $89,3 \%$, sendo que o incremento mínimo foi de $22 \%$ e o máximo de $435 \%$.

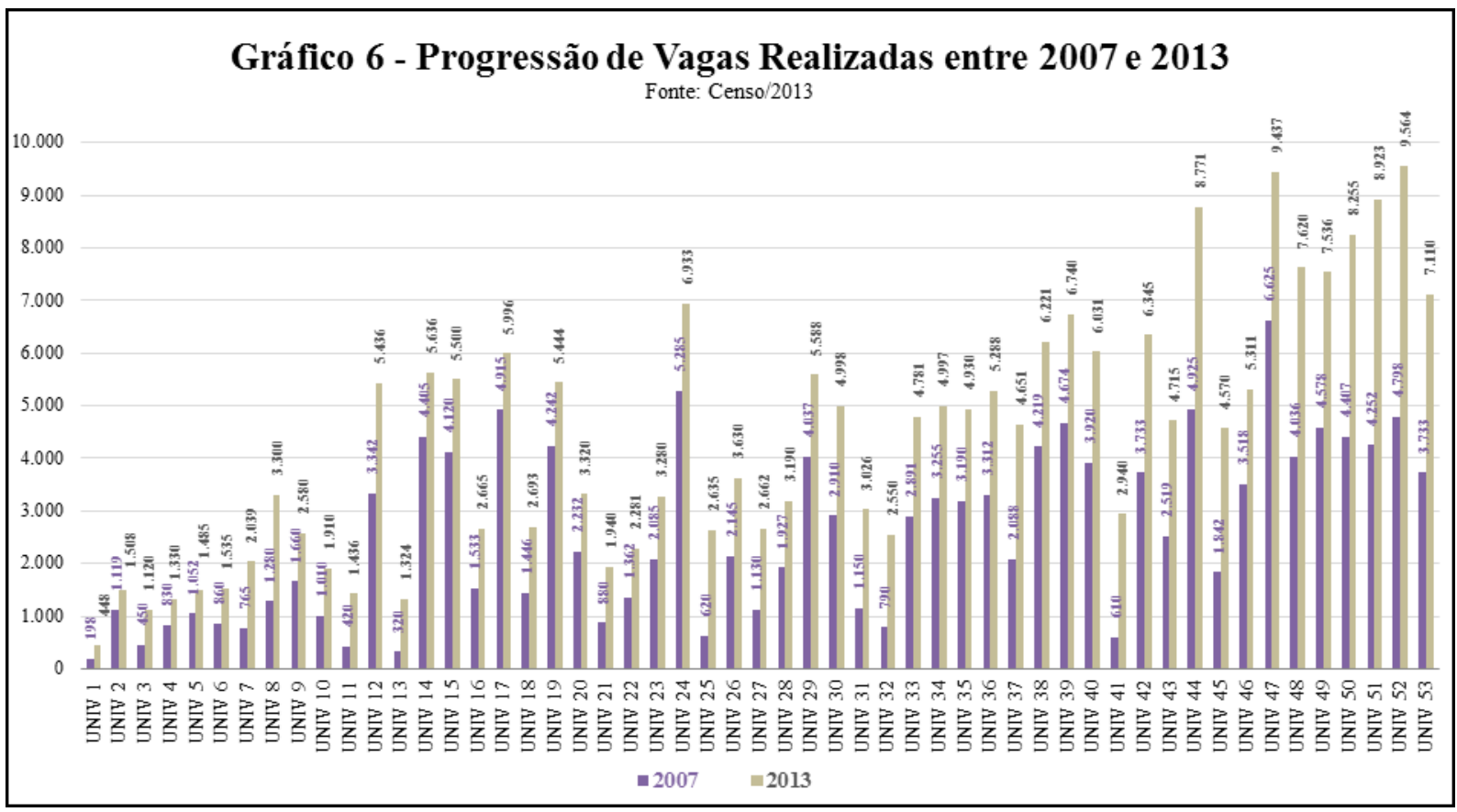

\subsection{REUNI - OBRAS}

Considerando um universo de 2804 obras em 53 universidades federais, o índice de conclusão de obras do REUNI até setembro de 2014 era de $78 \%$, representando 2.178 obras concluídas (Gráfico 7). As obras em execução representavam ainda 13\% do universo, e, segundo dados do MEC, extraídos do Módulo de Obras/SIMEC, a maioria delas, deverão ser concluídas em 2015. Considerando que o Programa já se encontra próximo ao seu período de encerramento, observou-se que $5 \%$ das obras ainda estão em processo de licitação. Este fato pode denotar que surgiram novas necessidades não previstas na etapa do planejamento dos Planos Diretores de Infraestrutura Física de algumas instituições que acabaram por atrasar todo o processo. É importante esclarecer, porém, que parte destas obras encontram-se em processo de licitação pois tiveram seus contratos cancelados ao longo de seu processo de execução. 

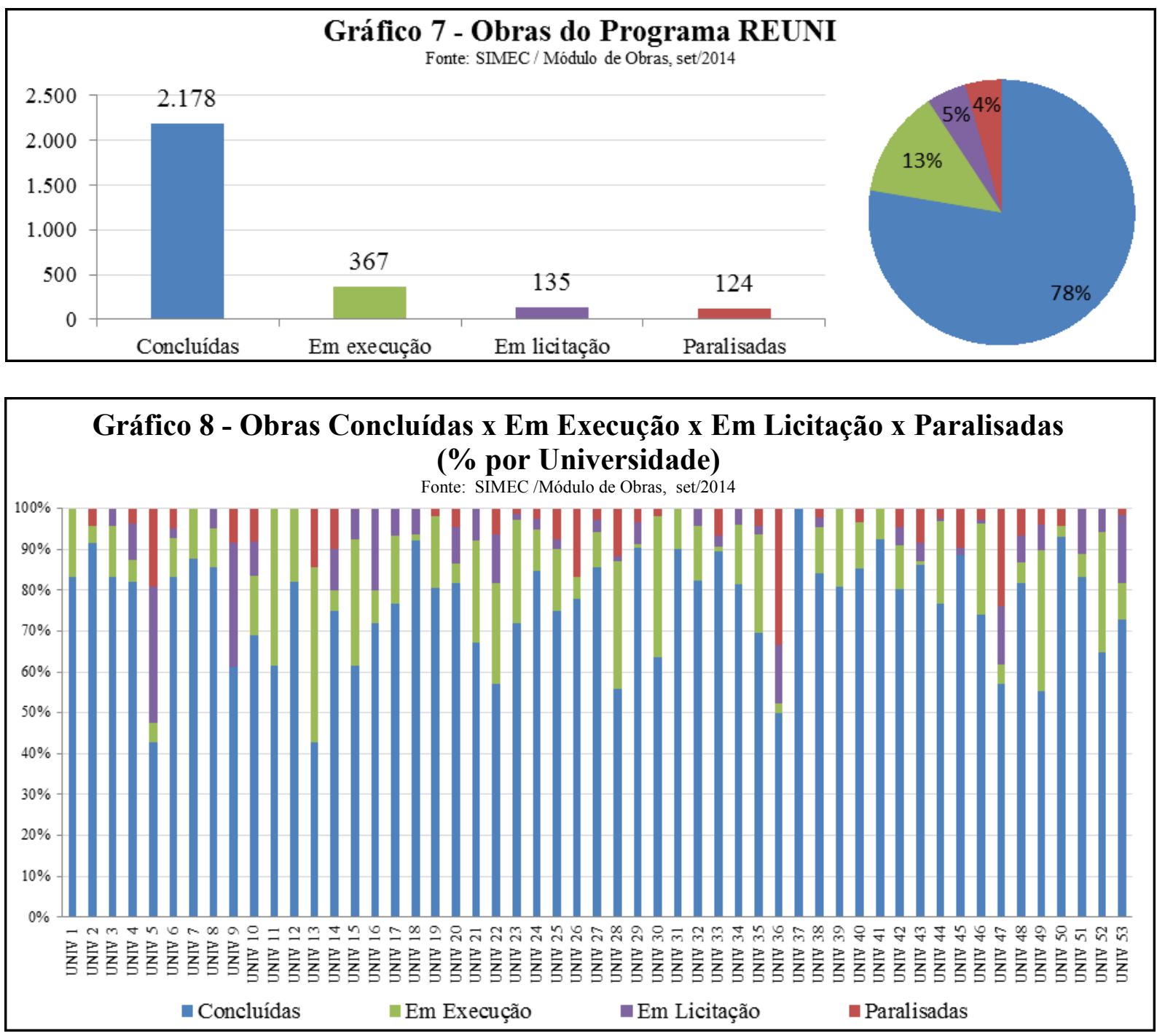

O percentual de 4\% de obras paralisadas parece ser aceitável diante da dimensão deste Programa. Apenas para seis universidades $(5,13,26,28,36$ e 47) estes índices alcançam percentuais superiores a 10\% (Gráfico 8), porém é importante lembrar que o número de obras paralisadas variou ao longo da implantação do REUNI. Várias obras que hoje se encontram concluídas, sofreram paralisações por diversos motivos (abandono pela empresa contratada, ritmo de execução abaixo do programado, falhas diversas em projetos, descumprimento de contratos, embargos diversos), o que pode ter acarretado em prejuízos acadêmicos e de gestão. No Gráfico 8 também é apresentado um quadro comparativo de obras concluídas, em execução, em licitação e paralisadas por IFES. Pode-se observar que quase a totalidade das universidades possuem percentuais de obras concluídas superiores ao de obras em execução, sendo exceção a universidade 13, que possui índices iguais para obras concluídas e em 
execução. Apenas duas universidades possuem índice de obras concluídas menor que 50\% (Univ. 5 e 13), e sete possuem este mesmo índice menor que 60\% (Univ. 5, 13, 22, 28, 36, 47 e 49). Cabe ressaltar aqui, que das universidades anteriormente citadas apenas uma (Univ. 36) alcançou sua meta de pactuação no que concerne a expansão de vagas da graduação presencial, demonstrando assim a importância da conclusão de obras para o cumprimento das metas pactuadas.

Além do exposto anteriormente, vale destacar mais alguns pontos passíveis de considerações. Primeiro, durante o período de implantação do REUNI , havia a possibilidade de se licitar e contratar uma obra apenas com o projeto básico (conforme o $\S 2$, do Art.40 da Lei 8.666/1993). Em um número significativo de obras licitadas para atender o REUNI, os orçamentos foram elaborados seguindo somente as indicações dos estudos preliminares e seus respectivos projetos básicos. A falta do projeto executivo, dos projetos complementares, da sondagem do terreno e de quantitativos precisos, resultantes da contratação das obras apenas com o projeto básico, certamente causou implicações no andamento das mesmas, acarretando, muitas vezes, em revisões de projetos ou até mesmo sua paralisação. Nota-se, por exemplo, que, nos contratos de obras firmados e executados por "Empreitada por Preço Global”, a falta de exatidão nos quantitativos, ora por deficiências na estimativa dos serviços, ora devido ao uso de técnicas construtivas equivocadas, induzem a elaboração de cronogramas físicofinanceiros não reais. Por este motivo, o planejamento e a efetiva execução dessas obras podem ficar comprometidos. Para compensar tais deficiências, os aditivos de valor e/ou prazo acabaram sendo utilizados de maneira a adequar o contrato às necessidades encontradas no momento da execução da obra. Porém, em alguns casos, os valores finais de contrato chegaram aos limites impostos no Art. $65, \S 1^{\circ}$ (até $25 \%$ para obras, serviços ou compras e $50 \%$ para reformas e equipamentos) sem que, o objeto contratado fosse concluído, desencadeando, possíveis consequências como: paralisação de obras, cancelamento de contratos e a realização de novas licitações.

Em segundo lugar, algumas cláusulas previstas no Art. 30 da Lei 8.666/1993 (limitação quanto à documentação relativa à qualificação técnica), Lei Complementar 123/2006 (tratamento diferenciado para micro e pequenas empresas) e Acórdão $\mathrm{n}^{\mathrm{o}}$ 2.255/2008, podem fragilizar o processo de contratação de obras de médio e grande porte, colocando em risco a qualidade da execução. Ou seja, como não se pode exigir no edital de licitação, que as empresas participantes do certame apresentem garantias precisas de 
comprovação da qualificação técnica, econômica e financeiras tais como: (i) comprovação do capital social mínimo, (ii) comprovação de vínculo entre o profissional responsável pela futura execução da obra e a empresa licitante e, (iii) exigência que a empresa licitante possua em seu quadro permanente, na data da licitação, engenheiro civil ou arquiteto; há o risco de que a empresa vencedora da licitação não tenha condições técnicas e/ou financeiras para a execução da obra. Pode-se perceber isso claramente na constatação de que a maioria das obras que possuem o status de paralisadas no Módulo de Obras/SIMEC possui como causas: abandono pela empresa construtora, ritmo de execução abaixo do planejado, inexecução do objeto, etc (Gráfico 9). Por outro lado, é importante aqui frisar que o entendimento do Tribunal de Contas da União é de que os itens anteriormente citados caracterizam restrição à livre concorrência.

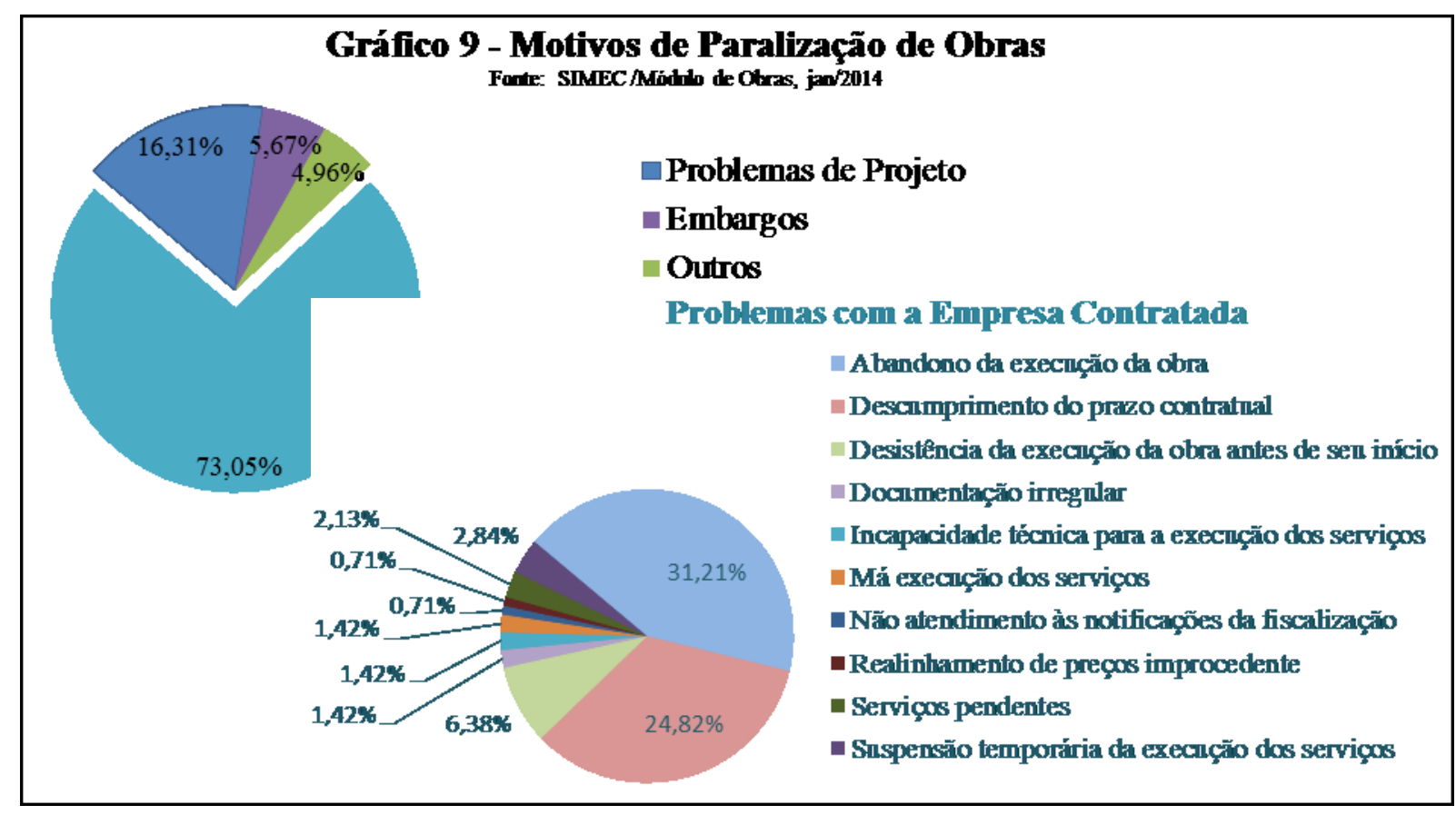

Por último, cabe lembrar o Decreto $n^{\circ} 7.423 / 2010$, que regulamenta a Lei $n^{\circ} 8.958$, de 20 de dezembro de 1994, que trata do repasse de recursos para Fundação de Apoio. Após a publicação deste Decreto, foi limitada a ação das Fundações de Apoio nos projetos de desenvolvimento institucional para a melhoria de infraestrutura das universidades. Naquela época, as obras que estavam em execução sofreram um descompasso no fluxo de execução dos serviços existentes, pois o decreto não trazia muito claramente esclarecimentos a respeito dos procedimentos a serem adotados para a conclusão das obras firmadas antes da publicação do mesmo. Cabe salientar, que as universidades tinham como prática a celebração de 
convênios com suas respectivas Fundações de Apoio para licitar, contratar, executar e fiscalizar obras de interesse Institucional. Tais convênios objetivavam dar maior agilidade no processo de contração tanto de obras quanto de profissionais especializados para consultoria e fiscalização das mesmas, porém em muitos casos isto não era verificado. Por fim, pode-se observar ainda que o período em que houve uma maior ampliação do quadro técnico de arquitetos e engenheiros coincide justamente com o fim desta prática de contração das obras através das fundações de apoio.

Ressalta-se que neste trabalho não foram analisadas as áreas das obras citadas, foram considerados os números totais, sendo que os mesmos foram relativizados em percentuais no Gráfico 8 .

\section{CONSIDERAÇÕES FINAIS}

Existe, atualmente, uma carência de estudos que relacionem obras com a formulação e implementação de políticas públicas. Apesar do aumento da oferta de serviços públicos normalmente passar por ampliação da estrutura instalada, pouco se vê na literatura estudos que façam referência ao tema. Além disso, outro ponto a ser destacado é a pouca importância que normalmente é dada às obras na fase de formulação das políticas.

Os resultados deste trabalho demonstram que pouca atenção foi dada a questão de obras na formulação do REUNI. Apesar de existir uma parte específica referente à infraestrutura (Plano Diretor de Infraestrutura Física), não havia uma métrica orientadora, que incluísse algum tipo de vinculação da ampliação da infraestrutura necessária ao atendimento de novas vagas, cursos e até novos câmpus. Neste ponto é importante lembrar que apesar do programa ter previsto uma otimização da infraestrutura instalada, muitas vezes como esta se caracterizava por instalações precárias, seria difícil apenas prever uma otimização sem maiores intervenções. O trabalho também procurou avaliar o fator obras na implementação do REUNI, pode-se analisar algumas medidas de desempenho denominadas por Oliveira (2013) como insumos (as obras, os recursos financeiros e mão-de-obra especializada) e resultados (o número de cursos e vagas pactuados e ofertados). Por meio dessas medidas de desempenho foi possível fazer uma avaliação de eficiência do REUNI, sobretudo, ao demonstrar que houve aumento nas vagas além do número pactuado e com $78 \%$ das obras concluídas, o que demonstra que mesmo sem ter todas as obras concluídas foi possível atingir e ultrapassar essa meta de pactuação. Quanto a eficácia não foi possível fazer uma análise mais detalhada desse 
critério, pois conforme já exposto, o artigo $2^{\circ}$ do Decreto ${ }^{0}{ }^{0} 6.096 / 2007$ estabelece diferentes metas para o REUNI, as quais vão além do resultado demonstrado neste trabalho que consiste no número de cursos e vagas pactuados e ofertados pelas universidades federais. Além disso, houve um aporte complementar de recursos em torno $62,55 \%$ a mais do planejado, o que pode ter contribuído para o indicador de $78 \%$ das obras já terem sido concluídas. Sobre a efetividade, vale destacar que o REUNI ainda é recente e que carece de um horizonte de tempo mais amplo para fazer uma análise do impacto dos seus resultados na taxa de alfabetização da população brasileira, condições de ingresso para o mercado de trabalho, entre outras questões que indiquem mudanças duradouras e significativas enquanto uma política pública voltada para educação superior.

Pode-se observar, que na primeira etapa de implementação do Programa, as universidades estavam desabituadas a executar obras. Não havia projetos de prédios de salas de aula, laboratórios, bibliotecas e outros que pudessem ser replicados. Após muitos anos com baixa aplicação de recursos, a expertise de elaboração de projetos ou até mesmo da construção de obras estava reduzida. Além disso, as equipes de engenharia das universidades estavam desmotivadas e desfalcadas. Por isso, acredita-se que em muitas universidades foi realizado um enorme esforço para que projetos fossem desenvolvidos e as obras fossem construídas. É importante ressaltar, que todo o processo de novas construções, ampliações e reformas estão se aprimorando nestes últimos anos. As universidades passaram a contratar, em muitos casos, o desenvolvimento de seus projetos e o acompanhamento e físcalização de suas obras de forma terceirizada, de modo a suprir suas deficiências de quadro técnico. Estas contratações visavam à redução da necessidade de técnicos de engenharia e arquitetura, tendo em vista o caráter transitório do volume de obras. Porém esta solução pode ocasionar alguns problemas, já que mesmo com estas contratações, há a necessidade de técnicos destas áreas nos quadros das universidades para avaliar a qualidade dos serviços entregues ou prestados. Destaca-se, ainda, nesta etapa de implementação do REUNI, a criação do Módulo de Obras do Sistema de Integrado de Monitoramento, Execução e Controle do Ministério da Educação - SIMEC. Este módulo permitiu aos gestores tanto das universidades, como também do MEC, que obras em localidades distantes pudessem ser acompanhadas conforme sua evolução. As informações inseridas neste sistema orientaram muitas vezes tomadas de decisão importantes, tais como: alocação de recursos, liberação de limites orçamentários, entre outras. Do mesmo modo, este 
sistema permitiu uma maior transparência na alocação de recursos, já que os órgãos de controle, em especial a Controladoria Geral da União tem acesso a seus dados.

Destaca-se que das universidades que possuem índice de obras concluídas menor que $60 \%$ apenas uma alcançou sua meta de pactuação no que concerne a expansão de vagas da graduação presencial, demonstrando assim a importância da conclusão de obras para o cumprimento das metas pactuadas. Ressalta-se, ainda, que muitas universidades utilizaram, para dar cumprimento às metas, instalações provisórias (espaços alugados, temporariamente cedidos ou mesmo improvisados, como contêineres adaptados ou outros). Nestes casos, resta saber se a qualidade do ensino não restou prejudicada.

Outro ponto a ser considerado é que, principalmente devido à interiorização proposta e a ampliação do acesso à educação superior gratuita, alguns espaços, inicialmente não planejados, começaram a ser demandados. Uma comprovação deste fato foi que no ano de 2012, durante o longo período de greve dos docentes e técnicos administrativos das universidades federais, a União Nacional dos Estudantes entregou um documento ao MEC, onde reivindicava uma série de itens relativos à infraestrutura das universidades, como por exemplo, espaços de assistência ao estudante (moradias estudantis e restaurantes universitários).

Por fim, cabe destacar que este trabalho foi um primeiro passo na análise do tema: obras nas políticas públicas. Existe, porém, a necessidade premente de ampliar as discussões a respeito da importância das obras na formulação e implementação de políticas públicas. Assim, muitos outros estudos poderão ainda ser realizados tanto na ótica das obras públicas em geral, quanto das obras do REUNI.

\section{REFERÊNCIAS}

BRASIL. Decreto Presidencial no . 6.096, 24 de abril de 2007.

Lei $\mathbf{n}^{\mathbf{0}} \mathbf{. 8 . 6 6 6 ,} 21$ de junho de 1993.

MINISTÉRIO DA EDUCAÇÃO. Sinopse das Ações do Ministério da Educação. Disponível em:<portal.mec.gov.br/index.php?option=com_banners\&task...bid...>. Acesso em: 28jul. 2013.

MINISTÉRIO DA EDUCAÇÃO. Secretaria de Educação Superior. Relatório de Gestão do exercício de 2012. Disponível em: <portal.mec.gov.br>. Acesso em: 30 jun. 2013. 


\section{. MINISTÉRIO DA EDUCAÇÃO. Análise sobre a expansão das Universidades}

Federais 2003 a 2012. Brasília, 2012.

ANDRADE, D.; CASTRO, C.; CAPPELLE, M.; PEREIRA, J. R. A Gestão Pública e o REUNI: entre o social e o gerencial. Revista da Universidade Vale do Rio Verde, Três Corações, v. 9, n. 2, p. 154-170, ago/dez 2011.

COHEN, A. Public Works: when "big government" plays its role. The New York Times, v. 157.54127, nov. 2007.

COSTA, F.L.; CASTANHAR, J.C. Avaliação de programas públicos: desafios conceituais e metodológicos. Revista de Administração Pública, v. 37, n.5, p. 969-92, Set./Out. 2003.

DRIESSEN, P. P. J.,GLASBERGEN, P.; VERDASS, C. O. Interactive policy-making - a model of management for public works. European Journal of Operational Research, v. 128, p. 322-337, jan 2001.

FARIA, C.A.P. (org.) Implementação de políticas públicas: teoria e prática. Belo Horizonte: Editora Puc Minas,2012.

FERREIRA, P. A.; ALENCAR, E.; PEREIRA, J. R. Revisitando o modelo processual de análise de políticas públicas a partir das relações entre Estado e Sociedade. Anais... VI ENAPEGS. São Paulo: 2012.

FREY, K. Políticas públicas: um debate conceitual e reflexões referentes à prática da análise de políticas públicas no Brasil. Planejamento e Políticas Públicas, Brasília, n. 21, jun. 2000, p.211-259.

HOWLETT, Michael; RAMESH, M.; PERL, Anthony. Política Pública: seus ciclos e subsistemas: uma abordagem integral. Rio de Janeiro: Elsevier, 2013.

LUGÃO, R. G.; ABRANTES, L. A.; BRUNOZI JÚNIOR, A. C.; PAIVA, A. L de. Planejamento, implementação e avaliação do REUNI: um estudo em universidades mineiras. 2012. Disponível em: https://repositorio.ufsc.br/xmlui/handle/123456789/97671. Acesso em 03 set. 2013.

LUGÃO, R. G.; ABRANTES, L. A.; BRUNOZI JÚNIOR, A. C.; SILVA, F. C. da; SOUZA, A. P. de. Reforma universitária no Brasil: uma análise dos documentos oficiais e da produção científica sobre o REUNI. Anais... X Colóquio Internacional sobre gestión universitária en América delSur. Mar del Plata, 2010.

MELO, A. K. D.; SANTANA, T. O REUNI e suas implicações na Universidade Federal de Sergipe. Anais... IV Colóquio Internacional: Educação e Contemporaneidade. ISSN 19823657. Disponível em: http://www.educonufs.com.br/ivcoloquio/cdcoloquio/eixo 13/e1302.pdf. Acesso em 4set. 2013.

OLIVEIRA, J. A. P. Desafios do planejamento em políticas públicas: diferentes visões e práticas. Revista de Administração Pública nº 2, v. 40, p. 273-288, 2006. 
OLIVEIRA, V.E. As fases do processo de políticas públicas. In: MARCHETTI, V. (org). Políticas Públicas em debate. São Bernardo do Campo: MP Editora, 2013, p. 15- 37.

PINTO, J. M. de R. O acesso à Educação Superior no Brasil. 2004 Disponível em: http://www.scielo.br/pdf/es/v25n88/a05v2588.pdf . Acesso em: 31 jul. 2013.

RAMOS, M. P.; SCHABBACH, L.M. O estado da arte da avaliação de políticas públicas:conceituação e exemplos de avaliação no Brasil. Revista de Administração Pública,v.46, n.5, set./out. 2012, p. 1271-1294.

REIS, E. P. Reflexões leigas para a formulação de uma agenda de pesquisa em políticas públicas. Revista Brasileira de Ciências Sociais, v. 18, nº 51, 2003.

RUA, M. das G. Análise de Políticas Públicas: Conceitos Básicos. 1997. Disponível em: http://projetos.dieese.org.br/projetos/SUPROF/Analisepoliticaspublicas.PDF. Acesso em: 5 jul. 2013.

SARAVIA, E. e FERRAREZI, Elisabete. Introdução à Teoria das Políticas Públicas Coletâneas - Volume 1. Brasília: ENAP, 2006.

SOUZA, C. Políticas públicas: uma revisão de literatura. Sociologias, Porto Alegre, ano 8, $\mathrm{n}^{\mathrm{o}}$ 16, jul/dez 2006, p. 20-45.

TRINDADE, H. (Org.) Universidade em Ruínas: na República dos Professores. $3^{\text {a }}$ Ed. Petrópolis: Vozes, 1999. p.223. 